\title{
Enhancement of Dissolution Profile of Poorly Water Soluble Loratadine by Solid Dispersion Technique
}

\author{
Md. Zahir Uddin, J akir Ahmed Chowdhury, Ikramul Hasan and Md. Selim Reza
}

Department of Pharmaceutical Technology, Faculty of Pharmacy, University of Dhaka, Dhaka- 1000, Bangladesh

(Received: August 02, 2016; Accepted: November 11, 2016; Published (web): December 27, 2016)

\begin{abstract}
This study was carried out to improve the dissolution properties of loratadine by solid dispersion technique. A series of solid dispersions of loratadine in PVP K-30 (1:1, 1:3 and 1:5) were prepared by kneading technique. The prepared solid dispersions were characterized by various physicochemical properties (fourier transform infrared spectroscopy, X-ray diffraction and scanning electron microscopy) and the dissolution characteristics were compared with loratadine and the physical mixtures of loratadine. It was revealed from the physicochemical analyses that there was a good compatibility between drug and carrier. On the other hand, the drug release from the prepared binary solid dispersions was significantly enhanced in comparison to both drug alone and the physical mixtures. Finally solid dispersion of loratadine: PVP K-30 prepared as 1:5 ratio was found to be described by non-Fickian release mechanism and was selected as the best formulation in this study.
\end{abstract}

Key words: Solid dispersion, hydrophilic carrier, loratadine, kneading technique

\section{INTRODUCTION}

Oral route of drug administration is the most common and preferred method of delivery due to convenience and ease of ingestion. ${ }^{1}$ The therapeutic efficacy of an orally administered drug depends mainly on its absorption by the gastrointestinal tract. ${ }^{2}$ However, for a drug substance to be absorbed and transported to the site of action, the absorbable form of the active compound must first be in solution in the gastrointestinal tract, preferentially at a site where absorption is greatest. Therefore, the dissolution rate of a drug, or rate in which the drug goes into solution, is an important parameter for determining how much drug is available for absorption. ${ }^{3}$ If a drug is difficult to get into solution, then the amount of drug available for absorption may be small and thereby present difficulties in achieving the desired therapeutic effect. $^{4}$ Numerous works have been carried out in

Correspondence to: Jakir Ahmed Chowdhury Tel: +8801556333050; Fax: +880-2-9667222

E-mail: jakir@du.ac.bd

Dhaka Univ. J. Pharm. Sci. 15(2): 195-201, 2016 (December) order to modify the dissolution kinetics of poorly soluble drugs to improve their bioavailability. Among them solid dispersion technology was mostly used. ${ }^{5-10}$ Number of insoluble drugs has shown to improve their dissolution character when converted to solid dispersion. ${ }^{11}$ Solid dispersion technology is a well known process used to increase the dissolution kinetics and oral absorption of poorly water soluble drugs using water soluble inert carriers. ${ }^{12}$ The use of hydrophilic polymers as carriers for the dissolution enhancement of poorly water-soluble drug is increasing. ${ }^{13,14}$ Various hydrophilic carriers such as polyethylene, ${ }^{15}$ polyvinylpyrrolidone ${ }^{16}$ and $\operatorname{sugars}^{17}$ have been investigated for improvement of dissolution characteristics and bioavailability of poorly water soluble drugs. Polyvinylpyrrolidone (PVP) has been used for the preparation of solid dispersion of loratadine using rotary evaporation and spray-drying solvent evaporation techniques. ${ }^{18}$ The objective of the present study was to improve the dissolution profile of loratadine by preparing solid 
dispersion employing kneading technique using polyvinylpyrrolidone as hydrophilic carrier.

\section{MATERIALS AND METHODS}

Materials. Loratadine and polyvinylpyrrolidone (PVP K-30) were obtained as a gift samples from Beximco Pharmaceuticals Ltd., Dhaka, Bangladesh. All other reagents and solvents used in the study were of analytical grade.

Preparation of physical mixtures. Physical mixtures (PM) of loratadine at three different mass ratios $(1: 1,1: 3 \& 1: 5$ by weight of loratadine and PVP K-30, respectively) were prepared by pulverizing in a glass mortar. The mixtures were passed through sieve no. 60 .
Preparation of solid dispersions by kneading technique. ${ }^{19}$ Solid dispersions (SD) of loratadine at three different mass ratios $(1: 1,1: 3 \& 1: 5$ by weight of loratadine and PVP K-30 respectively) were prepared by wetting with water-ethanol (1:1 ratio) till the slurry was formed and kneaded thoroughly for 30 minutes in a glass mortar. The pastes formed were then dried in oven at $45^{\circ} \mathrm{C}$ for 24 hours. The solid masses were triturated in glass mortar. The resulting powders were passed through sieve no. 40. Finally solid dispersions were stored in a desiccator until further evaluation. The formulations of physical mixtures and solid dispersions are listed in Table 1.

Table 1. Composition of physical mixtures and solid dispersions of loratadine.

\begin{tabular}{ccccccc}
\hline \multirow{2}{*}{ Formulation } & \multicolumn{2}{c}{ Composition of physical mixtures } & \multicolumn{2}{c}{ Composition of solid dispersions } \\
\cline { 2 - 7 } & PM-1 & PM-2 & PM-3 & SD-1 & SD-2 & SD-3 \\
\hline Loratadine & $10 \mathrm{~g}$ & $10 \mathrm{~g}$ & $10 \mathrm{~g}$ & $10 \mathrm{~g}$ & $10 \mathrm{~g}$ & $10 \mathrm{~g}$ \\
PVP K-30 & $10 \mathrm{~g}$ & $30 \mathrm{~g}$ & $50 \mathrm{~g}$ & $10 \mathrm{~g}$ & $30 \mathrm{~g}$ & $50 \mathrm{~g}$ \\
\hline
\end{tabular}

Fourier transform infrared (FTIR) spectroscopy. FTIR spectroscopic study was conducted using a Shimadzu FTIR IR Prestige- 21 spectrophotometer (Japan) and the spectrum was recorded in the wavelength region of 4400 to 500 $\mathrm{cm}^{-1}$. The procedure consisted of dispersing a sample (Pure loratadine, PM-3 \& SD-3) in $\mathrm{KBr}$ and compressing into disc by applying a pressure of 5 tons for 5 minutes in a hydraulic press. Spectrum was obtained by placing the disc in the light path.

Differential scanning calorimetry (DSC). The DSC study was carried out using DSC-60 (Shimadzu, Tokyo, Japan). The important components of the instrument are calorimeter (DSC 60), flow controller (FCL 60), thermal analyzer (TA 60) and operating software (TA 60). The samples (Pure loratadine, PM3 \& SD-3) were heated in sealed aluminum pans under nitrogen flow $(10 \mathrm{ml} / \mathrm{min})$ at a scanning rate of $10{ }^{\circ} \mathrm{C} / \mathrm{min}$ from 30 to $300^{\circ} \mathrm{C}$. Empty aluminum pan was used as a reference. The heat flow was also recorded as a function of temperature for each sample.
X-ray diffraction (XRD). X-ray powder diffraction patterns were obtained at room temperature using a PW $1710 \mathrm{X}$-ray diffractometer (Philips, Holland) with $\mathrm{Cu}$ as anode material and graphite monochromator, operated at a voltage of 35 $\mathrm{kV}$ and $20 \mathrm{~mA}$ current. The samples (Pure loratadine, PM-3 \& SD-3) were analyzed in the $2 \theta$ angle range of $0^{\circ}-70^{\circ}$ and the process parameters were set as: scan step size of $0.02^{\circ}(2 \theta)$, and scan step time of $0.5 \mathrm{~s}$.

Scanning electron microscopy (SEM). The morphology of pure loratadine, physical mixture (PM-3) and solid dispersion (SD-3) were investigated by scanning electron microscopy (SEM), Hitachi S $3400 \mathrm{~N}$, Japan. The samples were placed in aluminum stubs and then were mounted on doublesided adhesive tape for analysis by SEM. The accelerating voltage was $15 \mathrm{kV}$. The samples were analyzed at magnification of 2000 . The analysis utilized $11100 \mu \mathrm{m}$ working distance and $57000 \mathrm{nA}$ emission current in this study. 
In vitro dissolution studies. $^{20}$ In vitro dissolution studies were performed in $0.1 \mathrm{~N}$ hydrochloric acid at $37 \pm 0.5^{\circ} \mathrm{C}$, using 6-station USP Type II apparatus (Erweka DT 600, Germany) with paddle rotating at $50 \pm 2 \mathrm{rpm}$. Samples of both solid dispersion and physical mixtures for dissolution study were taken in such a way that each containing $10 \mathrm{mg}$ of drug. At fixed time intervals, samples withdrawn were filtered (pore size $0.45 \mu \mathrm{m}$ ) and spectrophotometrically assayed for drug content at $280 \mathrm{~nm}$. Each test was performed in triplicate.

Data treatment. Different release kinetics is assumed to reflect different release kinetics mechanism. Therefore four kinetics models including zero order release equation Eq. (I), first order equation Eq. (II), Higuchi Eq. (III) $)^{21}$ and KorsmeyerPeppas Eq. (IV) ${ }^{22}$ equations were applied to process in-vitro data.

$\mathrm{Q}=\mathrm{K}_{1} \mathrm{t}$

$\mathrm{Q}=100\left(1-\mathrm{e}^{-\mathrm{K}_{2} t}\right)$

$\mathrm{Q}=\mathrm{K}_{3} \mathrm{t}^{1 / 2}$

$\log \left(\frac{M_{t}}{M_{\infty}}\right)=\log k_{4}+n \log t$

Where $\mathrm{Q}$ is the release percentage at time t. $\mathrm{K}_{1}$, $\mathrm{K}_{2} \mathrm{~K}_{3}$ and $\mathrm{K}_{4}$ are the rate constant of zero order, first order, Higuchi and Korsmeyer-Peppas model respectively. The $\mathrm{Mt} / \mathrm{M} \propto$ is the fractional drug release at time $t$ and the $\mathrm{n}$ is a kinetic constant. The $\mathrm{n}$ values give us an idea about the drug release mechanism from different formulations.

The MDT (Mean dissolution time) of different formulations were calculated using dissolution data according to Mockel and Lippold (1993) Eq. (V). ${ }^{23}$

$\operatorname{MDT}=\left(\frac{n}{n+1}\right) k^{-1 / n}$

\section{RESULTS AND DISCUSSION}

\section{Fourier transform infrared (FTIR)} spectroscopy. Figure 1 showed the IR spectra of loratadine, its physical mixture (PM-3) and solid dispersion (SD-3). Pure loratadine spectra showed sharp characteristic peaks at 3440 (N-H stretching), 3000 (C-H stretching of methyl group), $1700(\mathrm{C}=\mathrm{O})$, 1440 and $1220 \mathrm{~cm}^{-1}$. It is concluded from the spectra that there is no interaction between the drug and the carrier as the most characteristic peaks appeared in the spectra of the physical mixture (PM-3) and solid dispersion (SD-3) at the same wave numbers.

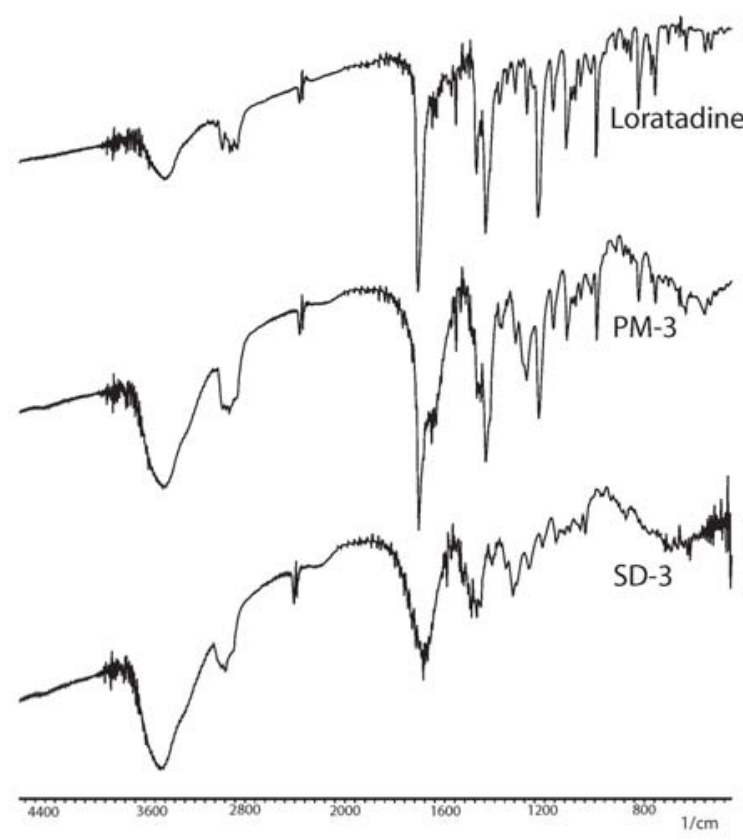

Figure 1. IR spectra of loratadine, PM-3 and SD-3.

Differential scanning calorimetry (DSC). DSC thermograms of loratadine, its physical mixture (PM3) and solid dispersion (SD-3) prepared by kneading method are shown in figure 2. Loratadine gave a characteristic and sharp endothermic peak at $138{ }^{\circ} \mathrm{C}$ which is close to its melting point. Thus it indicates the crystalline nature of the drug. The same peak in PM-3 at $135.42{ }^{\circ} \mathrm{C}$ also indicating the presence of crystalline form. However, the characteristic endothermic peak with reduced intensity at 133.50 ${ }^{\circ} \mathrm{C}$, corresponding to drug melting point, was observed in SD-3 indicating reduced crystallinity of the drug. This may be happened due to dispersion of the drug molecules in the PVP K-30.

X-ray diffraction (XRD). X-ray diffraction spectra are depicted in figure 3. The diffraction spectra of pure loratadine showed numerous distinct peaks indicating presence of high crystalline state. 
The characteristic loratadine peaks with high intensity were found to be at $7.61,12.75,15.19$, $16.35,16.57,19.60,21.13$ and 23.83 at $2 \theta$ degrees. On the other hand, it showed less intensity peaks of loratidine in the XRD pattern of physical mixture (PM-3). Moreover, much lowered intensity peaks of loratidine was observed in case of solid dispersion (SD-3). It is revealed from the study that the crystallinity of loratadine was reduced to a certain extent by making a solid dispersion of loratidine in PVP K-30.

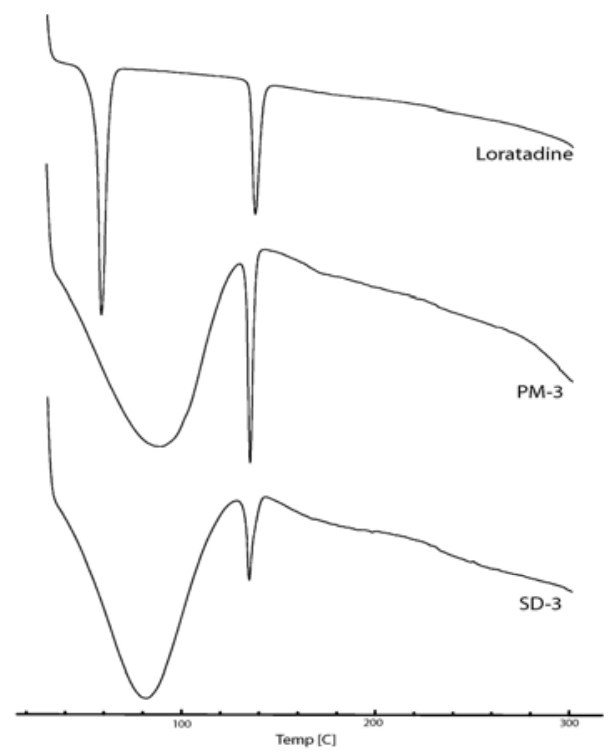

Figure 2. DSC thermogram of loratadine, PM-3 and SD-3.

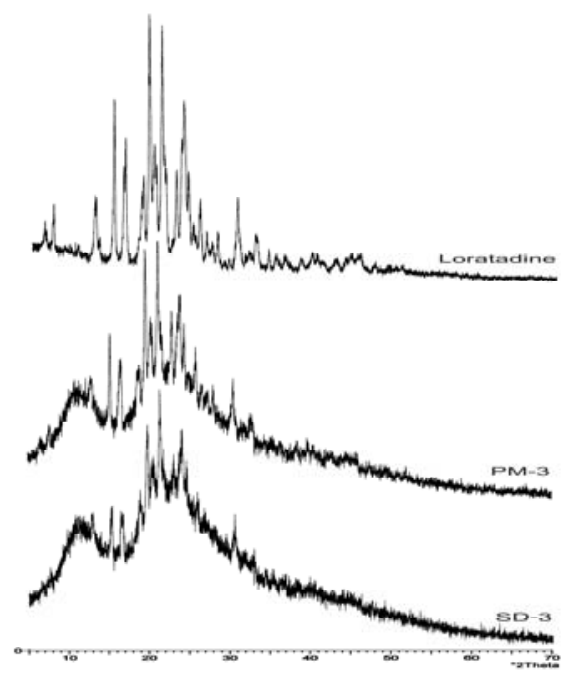

Figure 3. Powder X-ray diffraction spectra of loratadine, PM-3 and SD-3.
Scanning electron microscopy (SEM). The SEM results are shown in figure 4. Loratadine existed in lamellar-like crystals, consisted of large crystalline particles of rather irregular size, partially agglomerated in bundles. In case of physicals mixture (PM-3), the particle size and shape of loratadine was approximately the same. The original morphology of the components in solid dispersion was disappeared by forming an irregular appeared particle. It indicates that loratadine in solid dispersions was homogeneously dispersed into PVP K30 at the molecular level.

In vitro dissolution studies. Dissolution profiles data of loratadine are presented in figure 5. It is clear from the figure that the solid dispersion of loratadine has enhanced dissolution rate than those of physical mixture of loratadine. The zero order drug release rates $\left(K_{1}\right.$ in $\%$ release/time $)$ of different formulations as well as their corresponding binary systems with carriers are summarized in table 2 . Only $32.12 \%$ of the drug was released from pure loratadine powder after first 30 minutes. However, the drug release from PM-1, PM-2 and PM-3 after first 30 minutes were $32.94 \%, 37.86 \%$ and $40.67 \%$ respectively. Whereas, in case of SD-1, SD-2 and SD-3 the cumulative percent of drug released after first 30 minutes were $60.82 \%, \quad 65.41 \%$ and $69.39 \%$ respectively. Incorporation of drug with a hydrophilic carrier system offered an increased wetting and reduction in interfacial tension between hydrophobic drug and dissolution medium. ${ }^{24}$ It was observed during the dissolution studies that drug release from the solid dispersion was found to be faster. At the same time, the dissolution rate was also increased with the increase of proportion of PVP K-30 in solid dispersion. The SD-3 formulation of solid dispersion prepared using 1:5 drug carrier ratios showed the maximum dissolution rate of drug. It was almost 2.06 fold increased dissolution rate compared to the pure drug. 

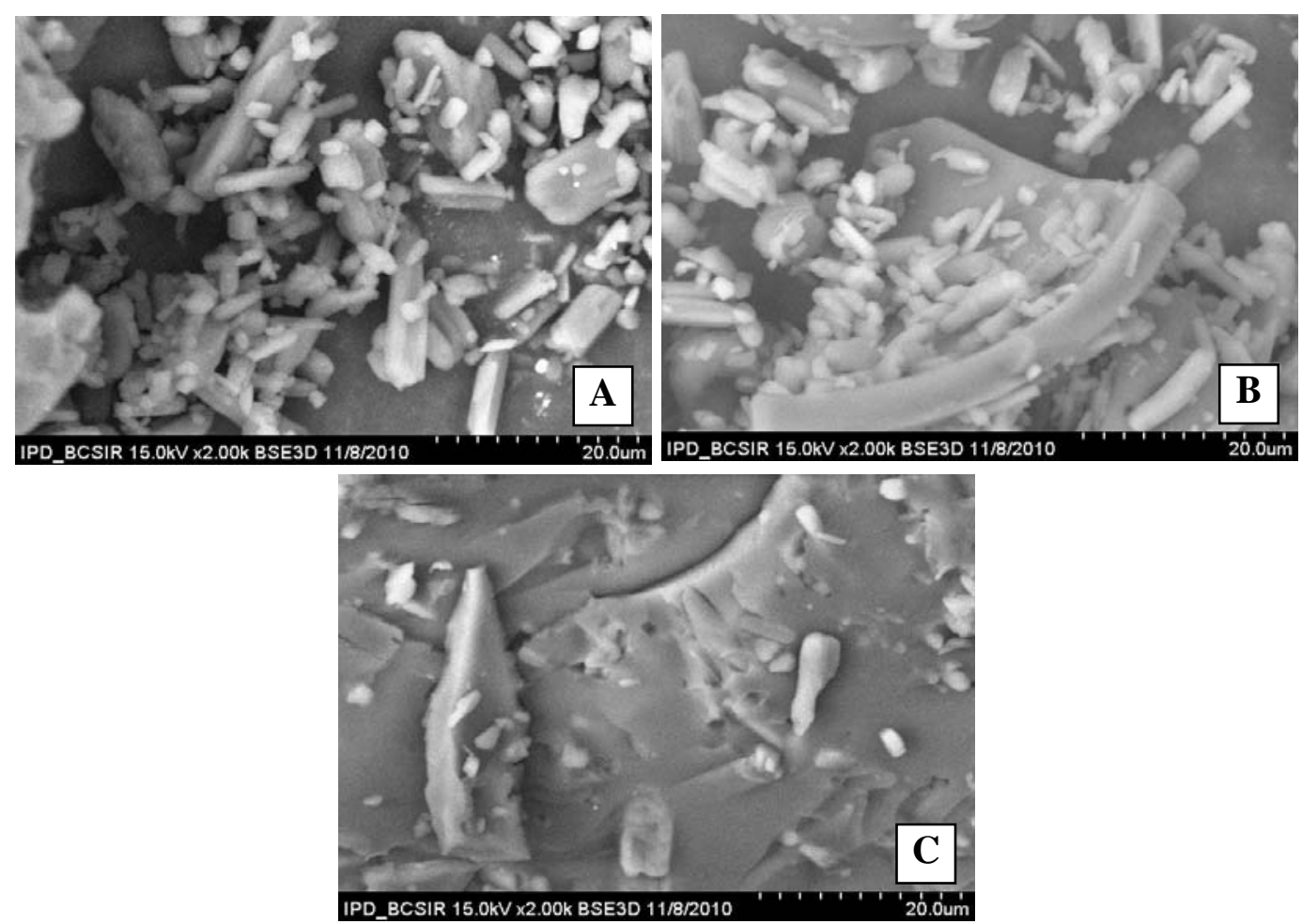

Figure 4. Scanning electron micrographs of (A) loratadine at X-2000, (B) PM-3 at X-2000 and (C) SD-3 at X-2000.

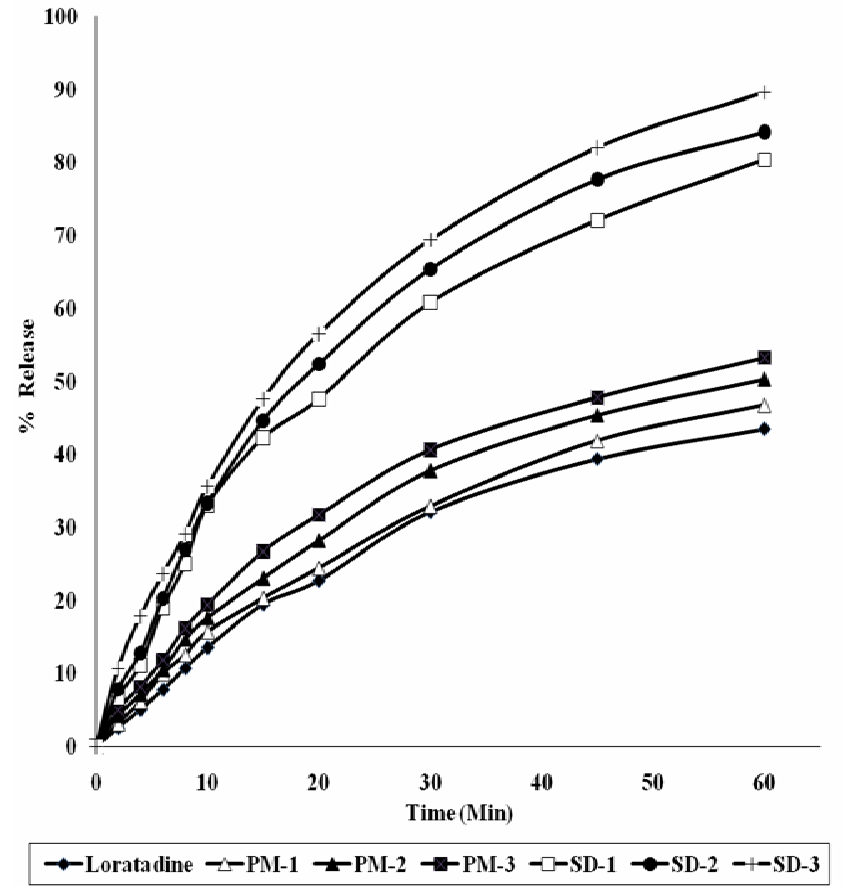

Figure 5. Dissolution profiles of loratadine and its binary systems. 
Table 2. Zero order drug release rate constant $\left(K_{1}\right)$, first order drug release rate constant $\left(K_{2}\right)$, rate constant of Higuchi model $\left(K_{3}\right)$, kinetic constant $(n)$ of Korsmeyer-Peppas model $\left(K_{4}\right)$, coefficient of determination $\left(R^{2}\right)$ for different model which indicates the goodness of fit of a model, mean dissolution time (MDT), time to release $50 \%$ of drug $\left(\mathrm{T}_{50 \%}\right)$.

\begin{tabular}{|c|c|c|c|c|c|c|c|c|c|c|}
\hline \multirow[t]{2}{*}{ System } & \multicolumn{2}{|c|}{ Zero Order } & \multicolumn{2}{|c|}{ First Order } & \multicolumn{2}{|c|}{ Higuchi } & \multicolumn{2}{|c|}{ Korsmeyer } & \multirow{2}{*}{$\begin{array}{l}\text { MDT } \\
(\min )\end{array}$} & \multirow{2}{*}{$\begin{array}{l}\mathrm{T}_{50 \%} \\
\text { (min) }\end{array}$} \\
\hline & $\mathrm{K}_{1}$ & $\mathrm{R}^{2}$ & $\mathrm{~K}_{2}$ & $\mathrm{R}^{2}$ & $\mathrm{~K}_{3}$ & $\mathrm{R}^{2}$ & $\mathrm{n}$ & $\mathrm{R}^{2}$ & & \\
\hline Loratadine & 0.751 & 0.942 & -0.004 & 0.970 & 6.378 & 0.974 & 0.848 & 0.981 & 56.031 & 53.920 \\
\hline PM-1 & 0.786 & 0.947 & -0.005 & 0.978 & 6.679 & 0.981 & 0.787 & 0.982 & 56.240 & 52.929 \\
\hline PM-2 & 0.846 & 0.931 & -0.005 & 0.969 & 7.253 & 0.982 & 0.747 & 0.984 & 51.262 & 47.401 \\
\hline PM-3 & 0.883 & 0.914 & -0.006 & 0.961 & 7.638 & 0.981 & 0.715 & 0.982 & 47.197 & 42.939 \\
\hline SD-1 & 1.324 & 0.902 & -0.012 & 0.989 & 11.51 & 0.980 & 0.740 & 0.963 & 25.751 & 23.731 \\
\hline SD-2 & 1.400 & 0.897 & -0.014 & 0.991 & 12.20 & 0.979 & 0.719 & 0.971 & 23.626 & 21.540 \\
\hline SD-3 & 1.451 & 0.900 & -0.016 & 0.998 & 12.67 & 0.986 & 0.639 & 0.985 & 21.998 & 19.071 \\
\hline
\end{tabular}

Release kinetics. The release kinetics of loratadine from different binary systems and the mean dissolution time (MDT) are depicted in table 2. Pure loratadine and the physical mixtures (PM-1, PM-2 \& PM-3) were best fitted with Korsmeyer model; while the solid dispersions (SD-1, SD-2 \& SD-3) were best fitted with first order model. The value of release exponent (n) of all the samples were in the range of $0.715-0.848$ which indicates nonFickian release, that is combination of diffusion of drug through the carrier with erosion of carrier.

MDT value is used to characterize the drug release rate. A lower value of MDT indicates a higher drug release rate and vice versa. From table 2 it can be observed that MDT decreased with increased carrier load which means if the carrier load was increased, drug dissolution was also increased in a step wise fashion.

\section{CONCLUSION}

The study shows that the dissolution rate of loratadine can be enhanced to a great extent by solid dispersion technique using an industrially feasible kneading method. The solid dispersion complex of drug displayed better dissolution profile as compared to pure drug. This, in turn, can result in reduced doses of drug, reduction in dose related adverse effects and improved bioavailability.

\section{ACKNOWLEDGEMENTS}

Authors would like to express gratitude to Beximco Pharmaceuticals Limited, Bangladesh
Council of Scientific and Industrial Research (BCSIR) and Center for Advanced Research in Sciences (CARS), University of Dhaka for kind cooperation at multiple stages of this study.

\section{REFERENCE}

1. Dhirendra, K., Lewis, S., Udupa, N. and Atin, K. 2009. Solid dispersions: a review. Pak. J. Pharm. Sci. 22, 234-246.

2. Venkatesh, D.N., Sangeetha, S., Samanta, M.K., Suresh, B., Ramesh, N., Faisal, $\quad$ M.M., Ilahi, A.A., Abuthahir, K.S.S., Haq, K.B.M.I. and Elanthirayan, S. 2008. Dissolution enhancement of domperidone using water soluble carrier by solid dispersion technology. Int. J. Pharm. Sci. Nanotech. 1, 221-226.

3. Proudfoot, S.G. 1988. Factors influencing bioavailability: factors influencing drug absorption from the gastrointestinal tract. In: Pharmaceutics: The Science of Dosage Form Design (Aulton, M.E.), Churchill Livingstone, New York, pp. 135-173.

4. Brittain, H.G. 1995. Solubility of Pharmaceutical Solids. In: Physical Characterization of Pharmaceutical Solids (Brittain, H.G., Eds), Marcel Dekker, New York, pp. 321386.

5. Chiou, W.L. and Riegelman, S. 1971. Pharmaceutical applications of solid dispersion system. J. Pharm. Sci. 60, 1281-1302.

6. Corrigan, O.I. 1985. Mechanisms of dissolution of fast release solid dispersions. Drug Dev. Ind. Pharm. 11, $697-$ 724.

7. Craig, D.Q.M. 1990. Poly ethylene glycols and drug release. Drug Dev. Ind. Pharm. 16, 2501-2526.

8. Ford, J.L. 1986. The current status of solid dispersions. Pharm. Acta Helv. 61, 69-88. 
9. Law, S.L., Lo, W.Y., Lin, F.M. and Chaing, C.H. 1992. Dissolution and absorption of nifedipine in poly ethylene glycol solid dispersion containing phosphatidyl choline. Int. J. Pharm. 84, 161-166.

10. Sekiguchi, K. and Obi, N. 1961. Studies on absorption of eutectic mixture. I. A comparison of the behavior of eutectic mixture sulfathiazone and that of ordinary sulfathiazole in man. Chem. Pharm. Bull. 9, 866-872.

11. Madhusudhan, B., Rambhav, D., Gudsoorkar, V.R., Shete, J.S. and Apte, S.S. 2002. Studies on sulphamethoxazole solid dispersions and their tablets. Indian J. Pharm. Sci. 64, 233238.

12. Delahaye, N., Duclos, R., Saiter, J.M. and Varnier, S. 1997. Characterization of solid dispersions phase transitions using a new optical thermal analyzer. Drug Dev. Ind. Pharm. 23, 293- 303.

13. Okimoto, K., Miyake, M., Ibuki, R., Yasumura, M., Ohnishi, N. and Nakai, T. 1997. Dissolution mechanism and rate of solid dispersion particles of nilvadipine with hydroxyl propyl methyl cellulose. Int. J. Pharm. 159, 85-93.

14. Yamada, T., Saito, N., Imai, T. and Otagiri, M. 1999. Effect of grinding with hydroxyl propyl cellulose on the dissolution and particle size of a poorly water soluble drug. Chem. Pharm. Bull. 47, 1311-1313.

15. Margarit, M.V., Rodryguez, I.C. and Cerezo, A. 1994. Physical characteristics and dissolution kinetics of solid dispersions of ketoprofen and poly ethylene glycol 6000. Int. J. Pharm. 108, 101-107.

16. Yagi, N., Terashima, Y., Kenmotsu, H., Sekikawa, H. and Takada, M. 1996. Dissolution behavior of probucol from solid dispersion system of probucol-polyvinylpyrrolidone. Chem. Pharm. Bull. 44, 241-244.
17. Danjo, K., Nataka, T. and Otsuka, A. 1997. Preparation and dissolution behavior of ethenzamide solid dispersion using various sugars as dispersion carriers. Chem. Pharm. Bull. 45, 1840- 1844.

18. Frizon, F., Eloy, J.d.O., Donaduzzi, C.M., Mitsui, M.L. and Marchetti, J.M. 2013. Dissolution rate enhancement of loratadine in polyvinylpyrrolidone K-30 solid dispersions by solvent methods. Powder Technol. 235, 532-539.

19. Modi, A. and Tayade, P. 2006. Enhancement of dissolution profile by solid dispersion (kneading) technique. AAPS PharmSciTech. 7, 1-6.

20. Nagersenkar, M.S., Garad, S.D. and Ramprakash, G. 2000. Design, optimization and evaluation of domperidone coevaporates. J. Control. Rel. 63, 31-39.

21. Higuchi, T. 1963. Mechanism of sustained action medication: theoretical analysis of rate of release of solid drugs dispersed in solid matrices. J. Pharm. Sci. 52, 1145-1149.

22. Korsmeyer, R.W., Gurny, R., Doelker, E., Buri, P. and Peppas, N.A. 1983. Mechanisms of solute release from porous hydrophilic polymers. Int. J. Pharm. 15, 25-35.

23. Mockel, J.E., and Lippold, B.C. 1993. Zero-order release from hydrocolloid matrices. Pharm. Res. 90, 1066-1070.

24. Narendar, R.M., Tasneem, R., Ramakrishna, S., Chowdary, K.P.R. and Prakash, D.V. 2004. $\beta$-cyclodextrin complexes of celecoxib: Molecular modeling, characterization and dissolution studies. AAPS PharmSciTech. 6, 1-7.

25. Sheu, M.T., Yeh, C.M. and Sokoloshi, T.D. 1994. Characterization and dissolution of fenofibrate solid dispersion systems. Int. J. Pharm. 103, 137-146. 